\title{
Tailbacks in Time, East Anglia
}

\author{
Richard D.G. Irvine
}

The A14 is an artery, squeezing traffic some 130 miles between the North Sea container port at Felixstowe and the tangle of roads at the Catthorpe Interchange in Leicestershire, where it feeds into two of Britain's major motorways. It is an urgent road, urgent in its flow of commuters and of containers. This urgency is only intensified by the routine sensation of being stuck; stuck in queues, stuck behind overturned tankers and spilled loads - sugar beet, onions, offal, ethanol.

The part of the A14 I am most familiar with from my fieldwork (see Irvine 2017) is the stretch that hugs the Cambridgeshire fens. Here the road is a margin above flat arable farmlands. Lorries join the $\mathrm{A} 14$ from the fens: carrying produce westwards from farms onto the motorway network, and so to wholesale and supermarket distribution centres; travelling eastwards with sugar beet for the sugar processing plant at Bury St Edmunds, a well-known A14 landmark.

This is productive land. Half of the total Grade 1 farmland in England - the highest grade under the Department for Environment, Food and Rural Affairs' Agricultural Land Classification - is in the East Anglian fens. The road keeps clear of the drained 
Richard Irvine $\mathbf{5 2}$

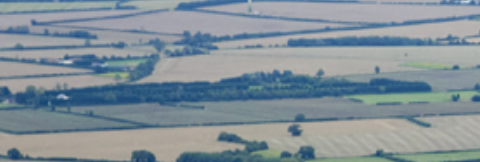

2.

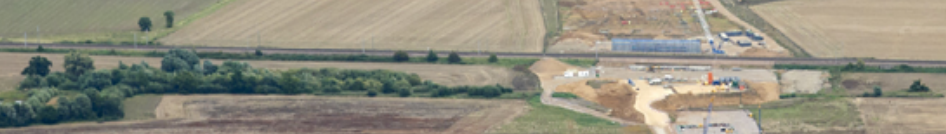

2 inis

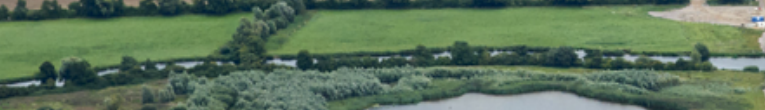

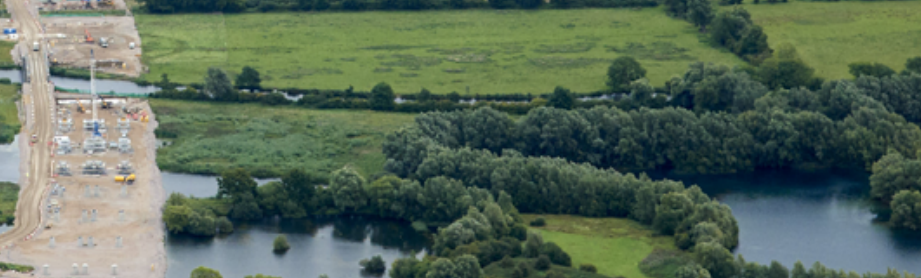

$+2$

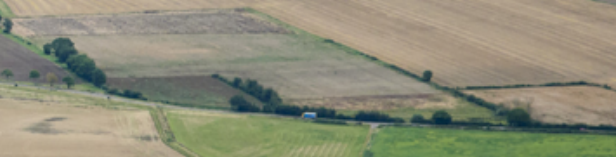

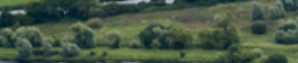

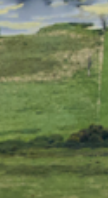

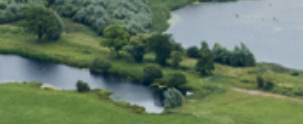

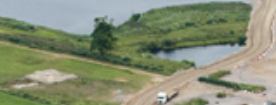

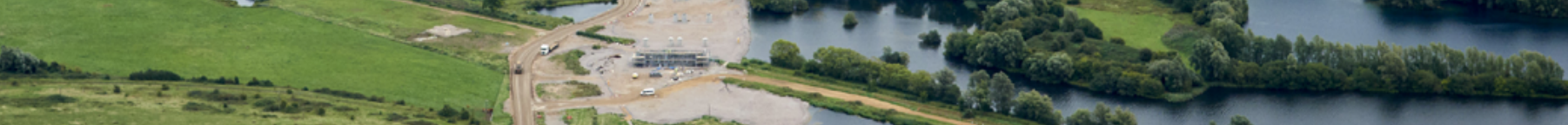

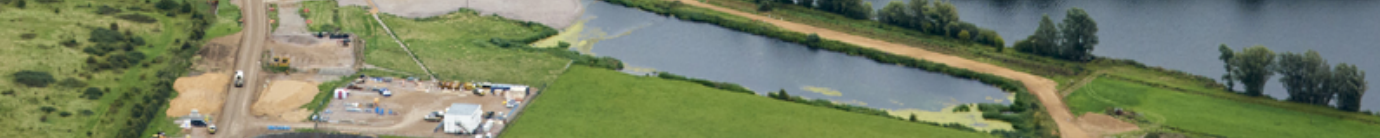

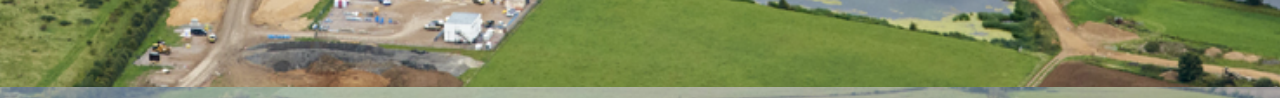

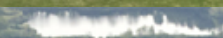

Centio

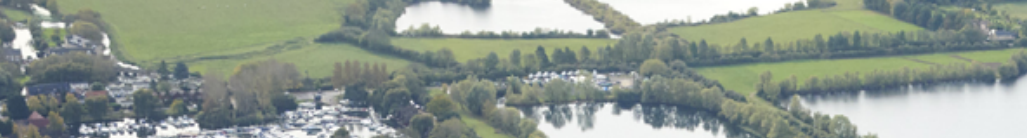

$2=x^{2}-2 x^{2}$

27
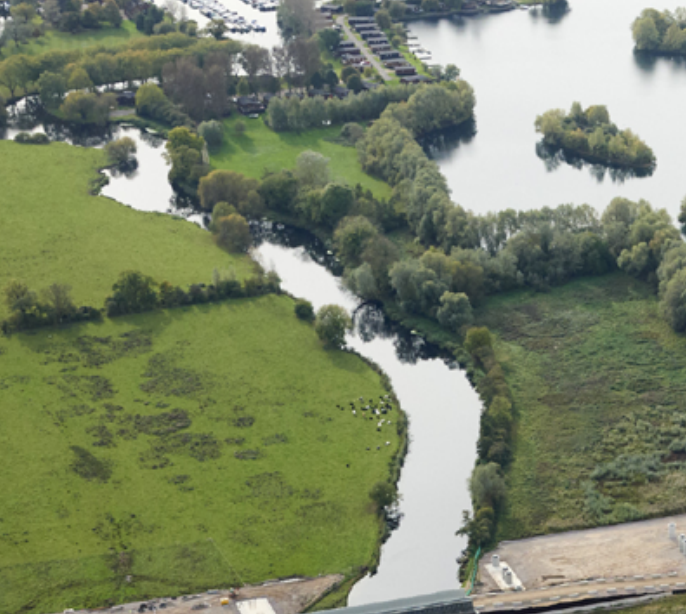

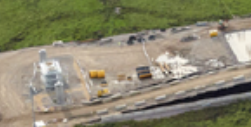<smiles>[3H]</smiles>

(1)
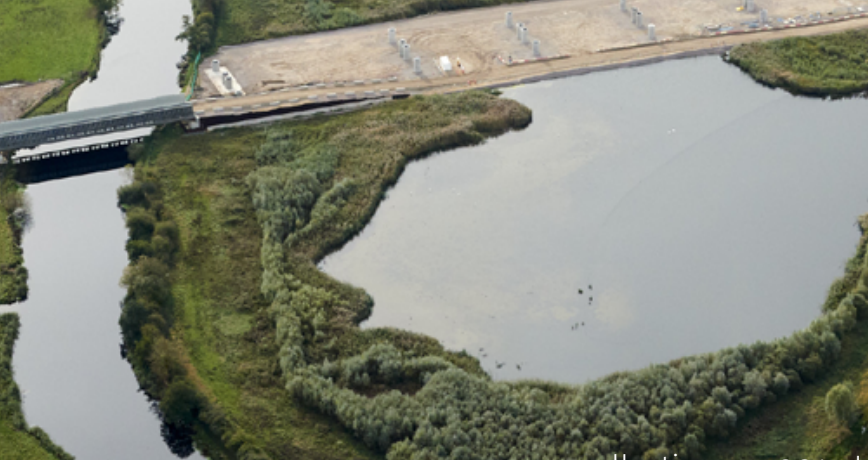

(1)

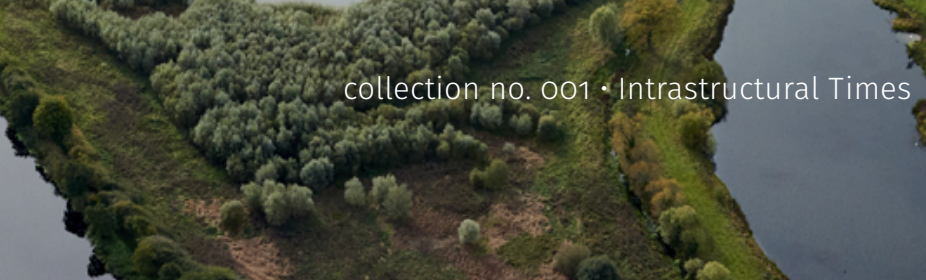

3.1. 0.6

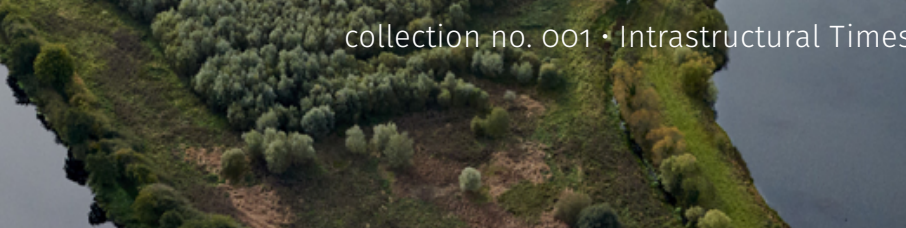

\section{Roadsides}

Construction of a viaduct over the River Great Ouse flood plain. The new route has to navigate terrain where the boundary

between land and water is historically uncertain,

December 2017.

Photo: Highways England. 
peatlands whose black soil makes the region so fertile, skirting the fen-edge, and with good reason. Intensive drainage works from the seventeenth century onward have transformed wetland into dry-land; yet this presents its own geostructural problems. Peat fen, thousands of years in formation, wastes away once drained. As the once-waterlogged organic matter is exposed to the air, it oxidises, and so land that has been drained and brought under cultivation rapidly lowers. This subsiding land poses infrastructural challenges, to be avoided if possible.

Of course, when the fen was a wetland, navigating through the soggy ground was itself a problem. During the Roman occupation of Britain, this fen-edge road was the strategic route around the wet. Here, old routes persist. Between the towns of Cambridge and Huntingdon, the tarmac of the A14 is superimposed on the Roman roadway, one section of the Via Devana (as it would come to be named in the nineteenth century) that linked the North West with the South East of England. This contributes to a temporality of repetition on the road: a daily ebb and flow along the road, nested within a rhythm of movement stretching back millennia.

In 2017, the A14 got a writer in residence as part of a scheme set up by the Institute of Continuing Education at the University of Cambridge. When I approached the poet L.H. Johnson, who took up the role, to ask her about her experiences exploring and writing about the road and its landscape, she remarked on its "spatially intimate" nature: the population density of the A14 corridor, the sense of being in the presence of so many stories through time. In the writing workshops she organised as part of her residency, ${ }_{1}^{1}$ participants responded to the currents of history along the road: some wrote about the Romans along the Via Devana, for example, while Johnson herself was inspired by the serenity of the American Cemetery - the rows of crosses and walls of names of Americans who died in the Second World War - in such close proximity to the stress-inducing junction that links the A14, A428 and M11. As she explained, the road connects these strands of history with the timelines of our own lives: "we live our lives in patterns and routines, and roads form a part of that pattern. We fall in love, we move house, we find a new job - and somehow, transport networks and roads in particular help to form part of that web. The A14 figures in the pattern of a lot of people's lives."

Now the stream of traffic is veering off the route. A four-year major roadbuilding scheme will re-route this stretch of road to the south of the existing course, increasing the number of carriageways and expanding capacity. As Chris Pinney (2002) has suggested, through the expansion of road traffic into an ever wider space we come to realise that we live in worlds created not through human agency alone but by and for human/motor hybrids. So, such road building is necessary for the continuation of our combustion-engine present (a continuation that, for now at least, relies on our ongoing treatment of oil from the planet's deep past as an infinite resource).

Yet if the building of new roads fixes the present by enabling the continuation of our taken-for-granted lifestyle, the processes of excavating the route and quarrying nearby material for the road juxtapose that present with the long-term history of a landscape in motion. Glacial till, the material deposited by ice sheets, is witness to the extent of the ice during glacial cycles in the Pleistocene epoch, between 2.5 


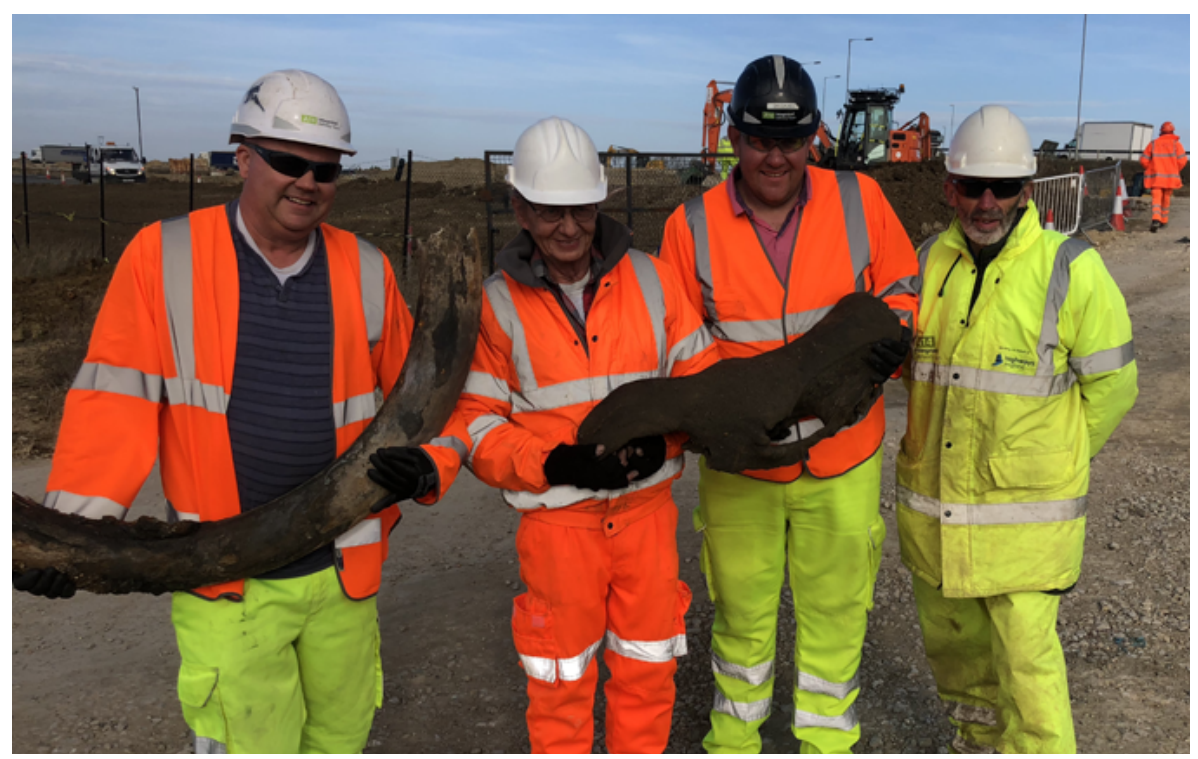

Workers show the remains of woolly mammoth and woolly rhino uncovered while quarrying for road materials at Fenstanton, October 2018.

Photo: Highways England.

million and 11,700 years before present. River terraces show the extent of what is now the River Great Ouse during the period of substantially higher sea level as the glaciers retreated. In October 2018, while quarrying for road materials in river terrace deposits at Fenstanton along the edge of the peat fen, workers discovered remains of woolly mammoth and woolly rhino, at least 100,000 years old - creatures adapted to life on cold grasslands south of the glaciers. A very different environmental past protrudes into the present.

Road construction aims towards the production of certainty. It responds to a desire for routes that are to be relied upon, and for movement not to be left in doubt; this is the expectation, however realistic or unrealistic, that shapes day-to-day life, and the construction supports those expectations. But attention to the time-depth of the terrain beneath the $A 14$ reminds us that the landscape is not a static container onto which we can project such certainty. This is a road being built for a future whose environmental conditions may be substantially different to those of the present.

Indeed, this has historically been a flood-prone region. Constructing a road that runs through areas with the highest grade of flood risk means taking account of flux in the surrounding landscape while trying to produce certainty in spite of it. Culverts on the scheme are designed to accommodate 1 in 100-year rates of flooding, ${ }^{2}$ factoring in the need for additional capacity due to rising sea levels caused by climate change. Loss of floodplain from road construction will be offset by the creation of new buffer areas, and sixty-eight "attenuation ponds" are to be dug along the route to accommodate surface runoff. The rhythm of water will be made to cohabit with the rhythm of the road - it must not be allowed to get in the way. Yet the past that protrudes in the course of roadworks calls the predictability of these rhythms into question: to fix the landscape at one moment in time is to ignore the story of flux.

What I have been trying to get at is the braiding of timelines and timespans along the A14: the speed of moving along the road, the lifetimes spent travelling up and 


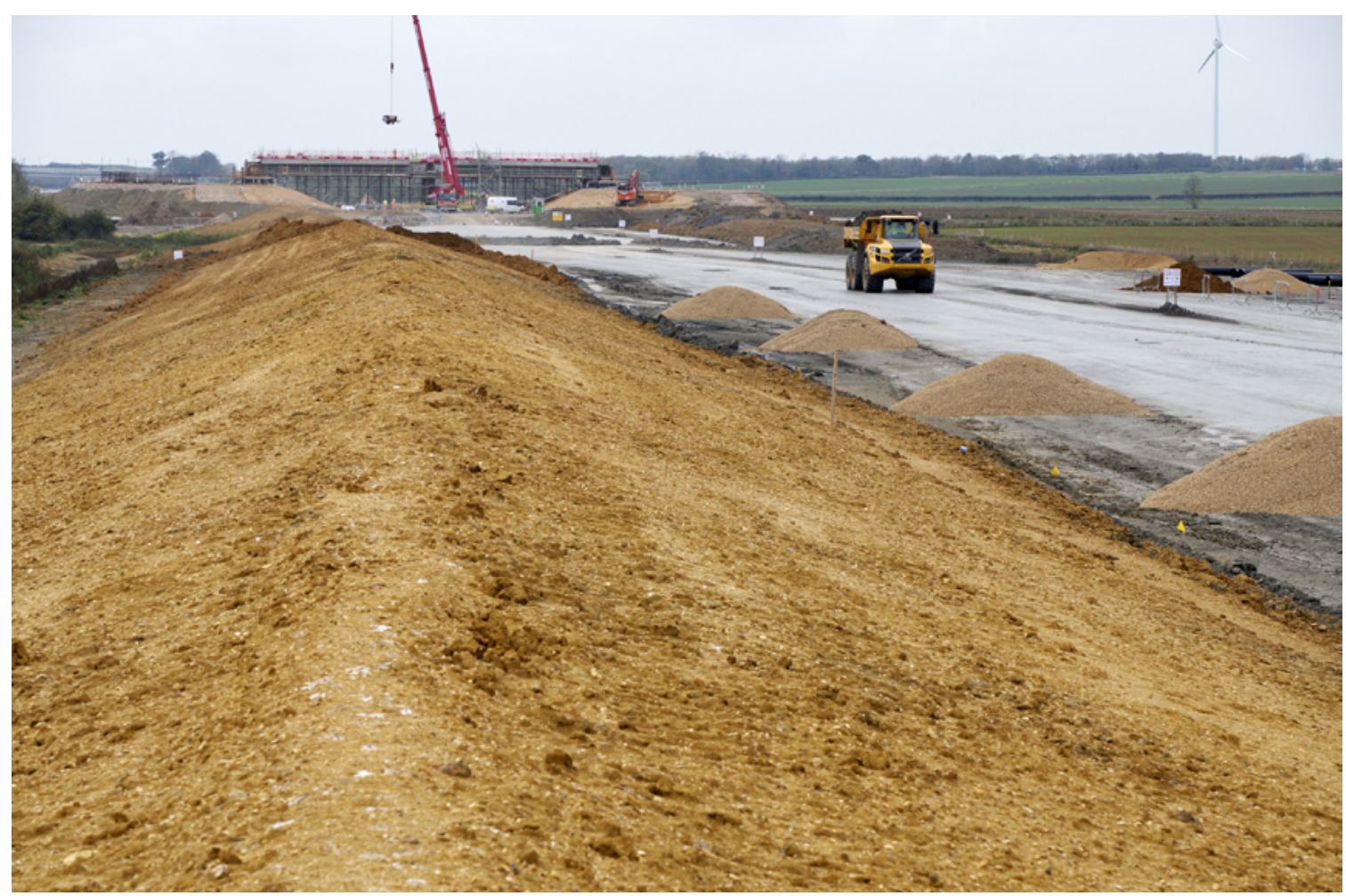

down that route, the pace of the landscape. The road has a time-depth that protrudes even when it is at its most static, as L.H. Johnson captures in one of the poems she produced while A14 writer in residence, "The Traffic Jam":

The traffic turns the world into a gansey, woven with handfuls of wool no longer than my hand, knots of cars and lorries pushed together with shaking fingers that see a future, where the wool's pulled tight by seawater and sorrow brings it to the door and the birds form a web of black and rain begins to fall, soft and shy as pained as love.

Eventually the vehicles around me start to experience a sense of adolescent liberty, and stay out past their curfew and go that little bit too far, too fast, stretching the knots and threads between us until it's nothing more than memory.

Life over tarmac pressed down on river terrace. It is here that we glimpse time on the $A 14$, somewhere between stuckness and flow.
Roadbuilding and bridge construction along the new route, December 2017.

Photo: Highways England. 


\section{References:}

Irvine, Richard D.G. 2017. “Anthropocene East Anglia." The Sociological Review 65 (1_suppl): 154-70. DOI: https://doi.org/10.1177/0081176917693745.

Johnson, L.H. (ed.) 2018. A14 voices: a collection of writing inspired by the A14. Cambridge: University of Cambridge Institute of Continuing Education.

Pinney, Christopher. 2002. “Automonster." In Autopia: Cars and Culture, edited by Peter Wollen and Joe Kerr, 227-32. London: Reaktion Books.

\section{Notes:}

${ }^{1}$ Some of the work produced is collected in Johnson 2018.

${ }^{2}$ That is, designed to take account of flood events calculated to have a 1 per cent probability of occurring in any given year.

Cite as: Irvine, Richard D.G. 2019. "Tailbacks in Time, East Anglia." Roadsides 1: 51-56. DOI: https://doi.org/10.26034/roadsides-20190018.

\section{Author:}

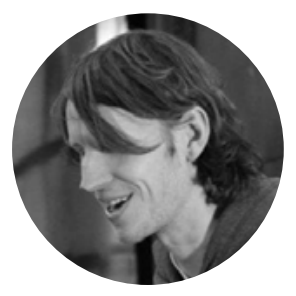

Richard D.G. Irvine is a Lecturer in Social Anthropology at the University of St Andrews. In his research across three ethnographic fieldsites - Orkney and East Anglia in the UK, and Tuv aimag in Mongolia - he focuses on human relationships with the changing landscape and the deep time of geological formation. His book The Anthropology of Deep Time is forthcoming with Cambridge University Press. 
Roadsides is a collaborative online publishing platform designed to be a forum devoted to exploring the social life of infrastructure.

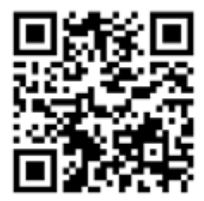

Visit us at: roadsides.roadworkasia.com

E-Mail: roadsides@roadworkasia.com

\section{Editorial Team:}

Julie Chu (University of Chicago)

Tina Harris (University of Amsterdam)

Agnieszka Joniak-Lüthi (University of Zurich)

Madlen Kobi (Academy of Architecture, Mendrisio)

Nadine Plachta (Heidelberg University's South Asia Institute, Kathmandu Office)

Galen Murton (LMU Munich and James Madison University, Harrisonburg)

Matthäus Rest (Max-Planck-Institute for the Science of Human History, Jena)

Alessandro Rippa (CU Boulder)

Martin Saxer (LMU Munich)

Christina Schwenkel (University of California, Riverside)

Max D. Woodworth (The Ohio State University)

Collection no. 001 was edited by: Agnieszka Joniak-Lüthi

Copyediting: David Hawkins

Layout: Antoni Kwiatkowski and Chantal Hinni

\section{ISSN 2624-9081}

\section{Creative Commons License}

This work is licensed under a Creative Commons Attribution-NonCommercial-ShareAlike 4.0 International License.

$$
\text { (c) (i) (2) (2) }
$$

